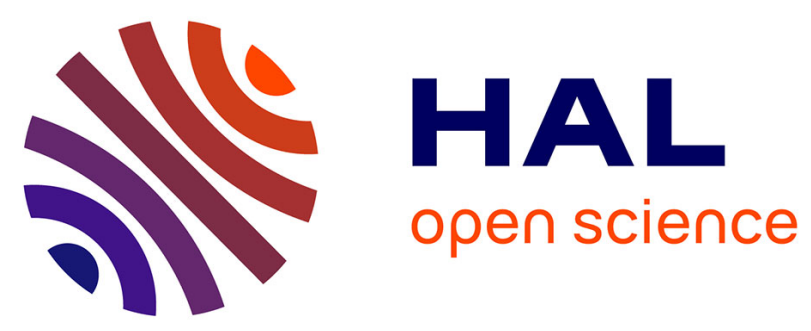

\title{
Synthesis and reactivity of an anionic NHC-borane featuring a weakly coordinating silicate anion
}

Thomas Deis, Fabrizio Medici, Antoine Poussard-Schulz, Gilles Lemière, Louis Fensterbank

\section{- To cite this version:}

Thomas Deis, Fabrizio Medici, Antoine Poussard-Schulz, Gilles Lemière, Louis Fensterbank. Synthesis and reactivity of an anionic NHC-borane featuring a weakly coordinating silicate anion. Journal of Organometallic Chemistry, 2021, 956, pp.122120. 10.1016/j.jorganchem.2021.122120 . hal-03414826

\author{
HAL Id: hal-03414826 \\ https://hal.science/hal-03414826
}

Submitted on 4 Nov 2021

HAL is a multi-disciplinary open access archive for the deposit and dissemination of scientific research documents, whether they are published or not. The documents may come from teaching and research institutions in France or abroad, or from public or private research centers.
L'archive ouverte pluridisciplinaire HAL, est destinée au dépôt et à la diffusion de documents scientifiques de niveau recherche, publiés ou non, émanant des établissements d'enseignement et de recherche français ou étrangers, des laboratoires publics ou privés. 


\title{
Synthesis and Reactivity of an Anionic NHC-Borane Featuring a Weakly Coor- dinating Silicate Anion
}

Thomas Deis, Fabrizio Medici, Antoine Poussard-Schulz, Gilles Lemière* and Louis Fensterbank*

Sorbonne Université, CNRS, Institut Parisien de Chimie Moléculaire, IPCM, 4 place Jussieu, F75005 Paris, France

Keywords: NHC-Borane, Anionic NHC, Silicon, Spirosilane, Pentacoordinated compounds, DFT calculations.

\begin{abstract}
We report herein the synthesis of a new NHC-stabilised borane complexe featuring a weakly coordinating anion, namely a pentaorganosilicate, on the NHC backbone. The synthesis can be achieved from a zwitterionic abnormal silicate-imidazolium adduct by deprotonation with a strong base followed by quenching with a borane transfer agent. Alternatively, the IPr- $\mathrm{BH}_{3}$ complex can also be deprotonated and the resulting vinylanion is trapped by a tetravalent spirosilane. The first structural data on a lithium derivative of an anionic NHC-borane complex functionalized by a silicate have been obtained and reveal an interaction between the three hydrogens of the borane and the lithium cation. Assessment of the reactivity highlights the higher hydridicity of the anionic NHCborane compared to the parent $\mathrm{IPr}-\mathrm{BH}_{3}$. Finally, electronic properties of this new species have been evaluated by means of DFT calculations and the presence of the silicate on the NHC backbone raises the HOMO which can in part explain the high hydride-donor abilities. This is consistent with the smooth reduction of an aldehyde without Lewis acid additive.
\end{abstract}

\section{Introduction}

Since the report by some of us in 2008 on the use of $\mathrm{N}$-Heterocyclic Carbene (NHC) - borane complexes as radical hydrogen donors,[1] this class of reagents has witnessed tremendous developments. [2] Their hydride donation ability was assessed[3] and has found applications in the reduction of carbonyl and imine derivatives.[4] For instance, they can generate in various conditions, including photoredox conditions,[5] NHC-stabilized boryl radicals[6] which can add to various insaturations[7] or serve as initiating species for photopolymerization.[8] NHC-boranes can also be precursors of boryl anions [9] or of stabilized boreniums[10] or can be involved in various reactions leading to boracycles.[11] In this work, we describe the access to a new NHC-borane bearing an anionic 
NHC ligand flanked by a silicate moiety. Structural and computational data give insight into this novel molecular object.

The group of Tamm[12] and the group of Stephan[13] found out in separate works that in the presence of tris(pentafluorophenyl)borane, the hindered NHC bearing two tert-butyl groups (ItBu) does not form a classical Lewis adduct principally due to steric factors. The resulting Frustrated Lewis Pair (FLP)[14] can efficiently activate small molecules such as hydrogen or carbon dioxide. However, without any substrate to interact with, the system evolves towards the formation of a stable abnormal adduct 1 which consists of an imidazolium ring bearing a weakly coordinating borate anion. Since imidazolium rings are common NHC precursors,[15] the deprotonation of neutral abnormal adduct of type 1 can potentially give a privileged entry to anionic NHC. However, as reported by the group of Tamm, the deprotonation of adduct $\mathbf{1}$ is difficult and leads to degradation when strong alkyllithiums bases are used.[16] Thereby, another strategy to synthesize anionic NHC complexes 3 was employed by the same group (Scheme 1). ItBu was first deprotonated using $n$-BuLi to form the organolithium species 4 that can subsequently react with the tris(pentafluorophenyl)borane. The intermediate carbene-lithium complex $\mathbf{2}$ allowed the synthesis of various transition metalcomplexes[17] and the anionic nature of the NHC ligand provided exceptional properties thereof. [18]

Recently, we have reported on the interactions of Lewis acidic spirosilane 5[19] featuring two Martin type ligands with NHC Lewis bases of imidazolylidene type.[20] Classical Lewis adducts $\mathbf{6}$ are obtained with relatively small NHCs like IMe and IMes (1,3-bis(2,4,6trimethylphenyl)imidazol-2-ylidene). Interestingly, when silane $\mathbf{5}$ was confronted to bulkier NHCs, such as IPr (1,3-Bis(2,6-diisopropylphenyl)imidazol-2-ylidene) and ItBu, a FLP character was observed and the abnormal adducts 7 were obtained. Gratifyingly in our case, deprotonation of the imidazolium silicates $\mathbf{7}$ could proceed smoothly with $n$-BuLi to afford directly the anionic carbene 8 complexed to a lithium cation (Scheme 1). From this anionic NHC platform, we were able to access to the corresponding neutral $\mathrm{Au}(\mathrm{I})$ and $\mathrm{Cu}(\mathrm{I})$ complexes.[21] These results prompted us to investigate further and notably the possibility of stabilizing main group-based compounds such as borane. 
Tamm group

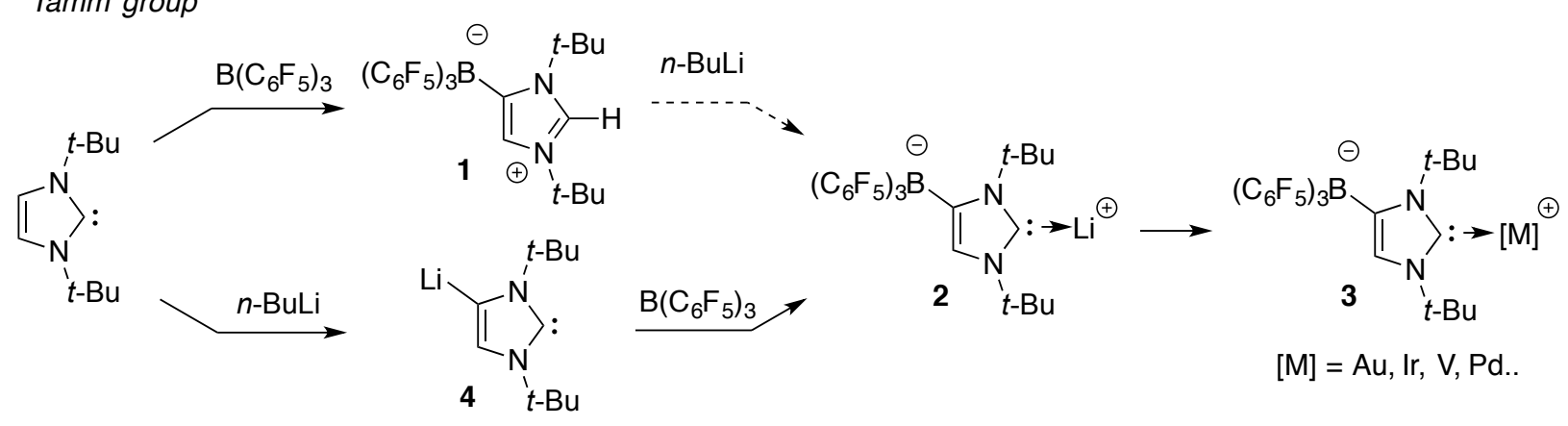

Our group

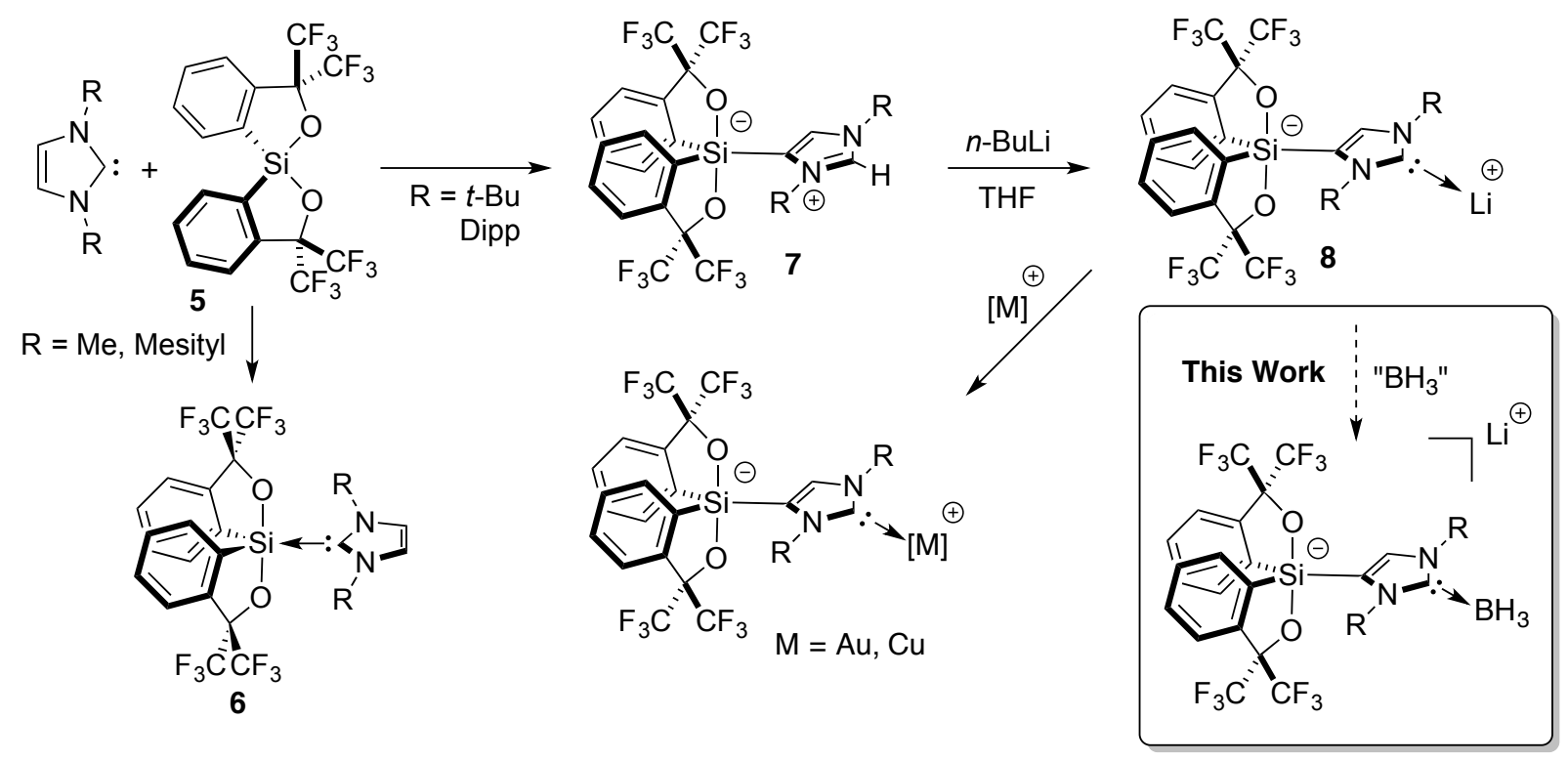

Scheme 1. Previous works on the synthesis of complexes bearing an anionic NHC ligand (Dipp: 2,6diisopropylphenyl, Mesityl: 2,4,6-trimethylphenyl)

\section{Results and Discussion}

\subsection{Synthesis of anionic $\mathrm{NHC}-\mathrm{BH}_{3}$ bearing a silicate}

The synthesis of $\mathrm{NHC}^{-} \mathrm{BH}_{3}$ derivatives can be achieved using various methods but the most straightforward one consists in mixing together the free NHC and a borane transfer agent.[2] As previously mentioned, our system has demonstrated to be a very good platform for the synthesis of new metal complexes bearing an anionic NHC ligand. Therefore we applied the same conditions of deprotonation using a stoichiometric amount of $n$-BuLi at $0{ }^{\circ} \mathrm{C}$ in the presence of zwitterion $7 \mathbf{a}$ bearing two Dipp substituents. The anionic NHC-Li intermediate was not isolated but quenched in situ by the addition of $\mathrm{BH}_{3}$. THF complex. Satisfyingly, anionic $\mathrm{IPr}-\mathrm{BH}_{3}$ lithium complex 9a was isolated by crystallisation in $40 \%$ yield (Scheme 2 ). The ${ }^{11} \mathrm{~B}$ NMR confirmed the tetracoordinate nature of the boron atom with the appearance of a broad quadruplet at $-34.6 \mathrm{ppm}$ and an associated coupling 
constant ${ }^{1} J_{B-\mathrm{H}}$ of $94.5 \mathrm{~Hz}$. The presence of lithium was also ascertained by means of ${ }^{7} \mathrm{Li}$ NMR with a chemical shift of $-0.6 \mathrm{ppm}$.
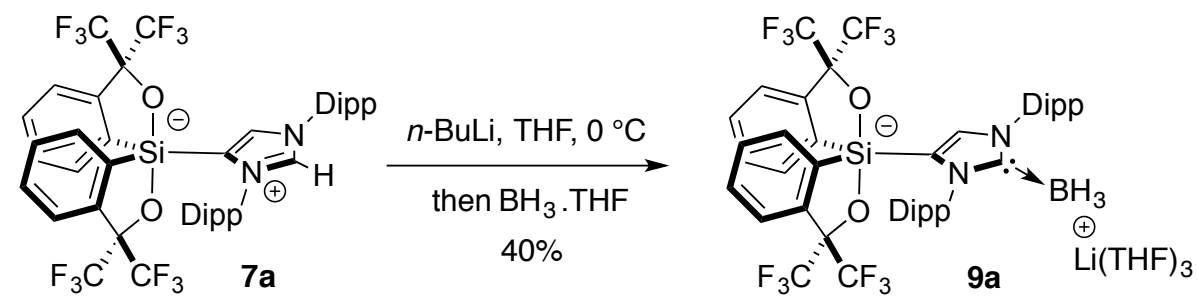

Scheme 2. Formation of anionic NHC-borane 9a

From the ${ }^{1} \mathrm{H}$ NMR spectrum of 9a, three molecules of THF seem to remain and are presumably coordinated to the lithium. One can ask whether the lithium cation is located at proximity of the weakly coordinating silicate anion or near the electron-enriched borane moiety. Interestingly, X-ray diffraction structure of compound 9a was obtained and some structural features are commented below (Figure 1).

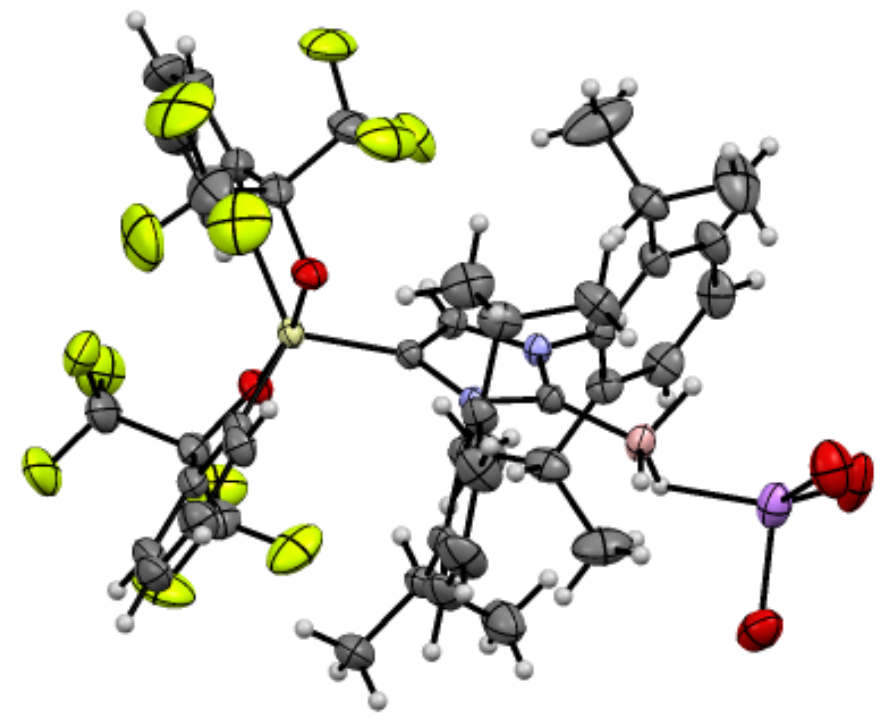

Figure 1. ORTEP representation of 9a, ellipsoid 50\% probability (For clarity reasons, the three molecules of THF are omitted. Only oxygen atoms are represented).

The compound belongs to the monoclinic $P 2{ }_{1} / c$ space group. It possesses a $\mathrm{Si}-\mathrm{C}$ bond length of $1.904 \AA$, similar to that found in the parent abnormal compound 7a (1.910 $\AA$ ).[21] The O-Si-O angle is a bit less constrained with an angle of $171.26^{\circ}$ (over $170.7^{\circ}$ for $7 \mathbf{a}$ ). The $\mathrm{C}-\mathrm{B}$ distance is 1.597 $\AA$ which results to be slightly smaller than that of the corresponding $\operatorname{IPr}_{-} \mathrm{BH}_{3}(1.62 \AA)$.[22] An intriguing characteristic in this structure is the proximity between the borane moiety and the lithium cation. The structure showed the presence of interactions between the lithium and the three hydrides of the borane part with a $\mathrm{C}-\mathrm{B}-\mathrm{Li}$ angle of $174.27^{\circ}$. In 2001 , Robinson and co-workers described an 
anionic $\mathrm{NHC}-\mathrm{BH}_{3}$ complex featuring a triethylborate on the $\mathrm{NHC}$ backbone with lithium as counterion,[23] and exhibiting a similar $\mathrm{Li}-\mathrm{H}-\mathrm{B}$ bonding. In compound $9 \mathbf{a}$, the $\mathrm{Li}-\mathrm{H}$ bond length is about $2.2 \AA(\mathrm{Li}-\mathrm{H} 12.105, \mathrm{Li}-\mathrm{H} 2$ 2.203, Li-H3 2.253), the Li-B distance is $2.315 \AA$ and the $\mathrm{B}-\mathrm{C}$ bond is $1.600 \AA$. These values are comparable to those found by Robinson ( $\mathrm{Li}-\mathrm{B} 2.332, \mathrm{~B}-\mathrm{C} 1.592 \AA)$.

Another pathway to the same anionic $\mathrm{NHC}-\mathrm{BH}_{3}$ derivative 9a was developed. It is known from the literature, that the IPr- $\mathrm{BH}_{3}$ complex can undergo a ring lithiation using $n$-butyllithium as a base and the resulting organolithium intermediate $\mathbf{1 0}$ can be trapped by various electrophiles to afford neutral mono-functionalized $\mathrm{IPr}-\mathrm{BH}_{3}$.[24] Interestingly, we were able to involve spirosilane 5 in such a reaction and the anionic $\mathrm{IPr}-\mathrm{BH}_{3}$ lithium complex was obtained with a good yield of $73 \%$ (Scheme 3).

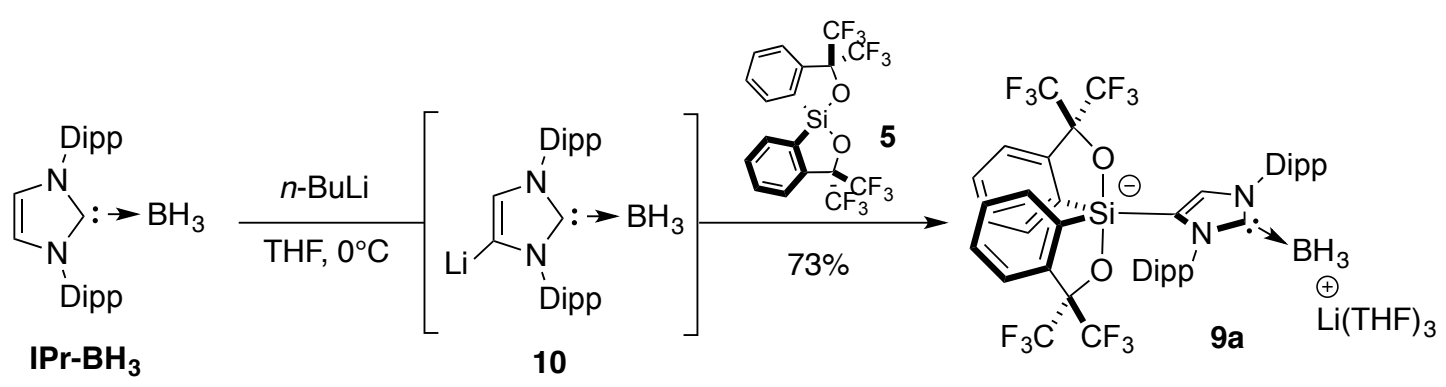

Scheme 3. Alternative route to prepare anionic $\mathrm{NHC}_{-}-\mathrm{BH}_{3}$ 9a

\subsection{Reactivity of anionic NHC-Borane 9a}

In order to compare the hydridicity of $\mathbf{9 a}$ and $\mathrm{IPr}-\mathrm{BH}_{3},[3 \mathrm{a}]$ we carried out some attempts of aldehyde reduction. Remarkably, complex 9a reduced almost instantaneously the 4-bromobenzaldehyde 11 into the alcohol 12 with a total conversion, the alcohol being the only product of the reaction (Ta-

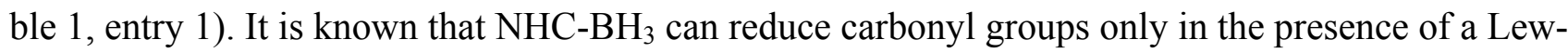
is[4] or Brønsted acid[25]. Effectively, without any additives, no conversion was observed with IPr$\mathrm{BH}_{3}$ at room temperature even after 24 hours (entry 2). One can argue that in the case of 9a, a lithium cation is present and can play the role of the Lewis acid to activate the aldehyde. Therefore, we add one equivalent of $\operatorname{LiNTf}_{2}$, a lithium salt presenting a weakly coordinated anion, already used as an efficient Lewis acid catalyst in organic transformations[26] but no conversion was also observed (entry 3). Since borane 9a displays three hydrogen atoms, we wondered how many of them could be delivered in the reduction process. When a 1:2 ratio of borane 9a to aldehyde $\mathbf{1 1}$ was employed, the reduction was still fast and total which means that at least two hydrides can participate (entry 4 and 5). Delivery of the third hydride seems to be more difficult probably due to the increase of steric hindrance. Full conversion of the aldehyde is observed after 3 hours. 
<smiles>O=Cc1ccc(Br)cc1</smiles>

11

Entry
1
2
3
4
5

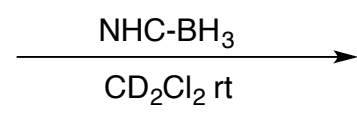

$\mathrm{NHC}-\mathrm{BH}_{3}: 11$

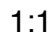

$1: 1$

$1: 1$

$1: 2$

$1: 3$<smiles>OCc1ccc(Br)cc1</smiles>

12

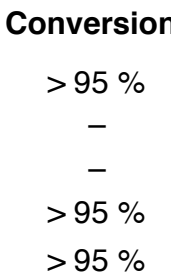

Table 1. Reduction of 4-bromobenzaldehyde using 9a and $\mathrm{IPr}-\mathrm{BH}_{3}$.

The high reducing ability observed for 9a could stem from a synergistic effect between the higher hydridicity[4a] and the presence of the lithium cation close to the borane site. Both factors are a direct consequence of the silicate present on the NHC backbone. A tentative mechanism for the reduction can be proposed as follows (Scheme 4). The aldehyde would coordinate to the lithium cation which is already interacting with the hydrogens of the borane. This complexation brings the electrophile nearby the hydride donor and the template effect would favour the hydride transfer to afford a benzyloxyborane derivative. Then, the same process can be repeated.

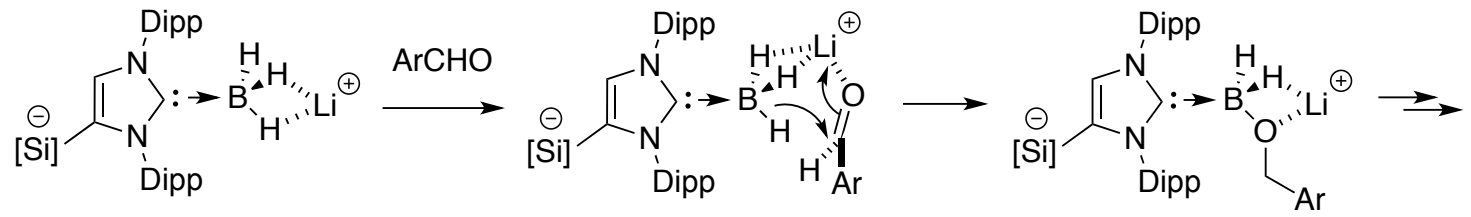

Scheme 4. Proposed mechanism for the reduction of aldehyde $\mathbf{1 1}$ by anionic NHC-borane 9a

\subsection{DFT Calculations}

We then used DFT calculations to evaluate the effects of the silicate part on the electronic properties of $\mathrm{IPr}-\mathrm{BH}_{3}$. For that purpose, the BDE of the $\mathrm{B}-\mathrm{H}$ bond in the anionic part of 9a $\left(\mathbf{a b I P r S i}-\mathbf{B H}_{3}\right.$ in Figure 2) was calculated at the M06-2X/6-311G+(2d,p)//M06-2X/6-31G(d,p). The BDE at this level is $82 \mathrm{kcal} . \mathrm{mol}^{-1}$ which is slightly higher than the one calculated for the parent $\operatorname{IPr}_{-} \mathrm{BH}_{3}\left(79 \mathrm{kcal}^{-\mathrm{mol}^{-}}\right.$ 1 , in accordance with the literature[1,27]). This unsurprisingly higher value suggests lower hydrogen donor capacities than IPr- $\mathrm{BH}_{3}$. Interestingly, the HOMOs of the two $\mathrm{NHC}-\mathrm{BH}_{3}$ species are very similar in shape with a probability density mainly localized on the heterocyclic ring and two hydrogen atoms of the borane moiety. It should be noted that the oxygen atoms of the silicate contributes very weakly in this molecular orbital. NBO analysis indicates no striking changes in the natural atomic charges except maybe for the carbon bearing the silicon atom which goes from +0.04 to -0.12 . The additional anionic charge is mainly redistributed on the spirosilicate. Although the shapes of the 
HOMOs are very similar, their energy levels are significantly different since the silicate moiety raises the HOMO by $2.8 \mathrm{eV}$, from -7.6 to $-4.8 \mathrm{eV}$. This result can suggest a higher reactivity of anionic NHC- $\mathrm{BH}_{3}$ 9a compared to IPr- $\mathrm{BH}_{3}$, which is observed experimentally.
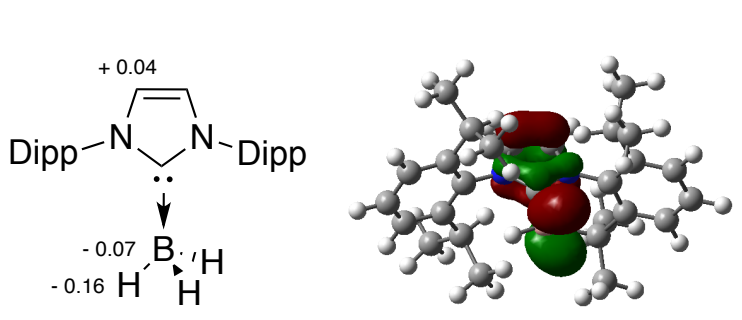

$\mathrm{IPr}-\mathrm{BH}_{3}$

$B D E$

$\mathrm{B}-\mathrm{H}=79 \mathrm{kcal} \cdot \mathrm{mol}^{-1}$
HOMO

$-7.6 \mathrm{eV}$

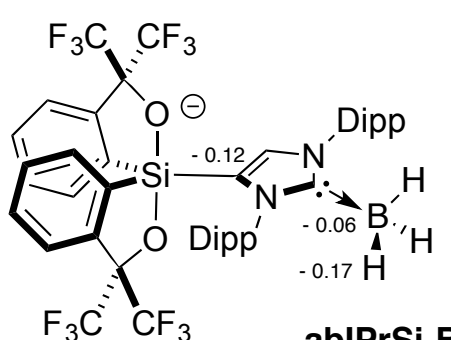

abIPrSi-BH

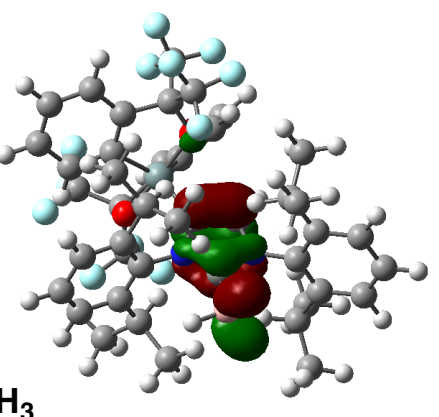

$B D E$

$\mathrm{B}-\mathrm{H}=82 \mathrm{kcal} \cdot \mathrm{mol}^{-1}$
HOMO

$-4.8 \mathrm{eV}$

Figure 2. Calculated B-H BDEs of $\mathrm{IPr}-\mathrm{BH}_{3}$ complexes $(\mathrm{M} 06-2 \mathrm{X} / 6-311 \mathrm{G}+(2 \mathrm{~d}, \mathrm{p}) / / \mathrm{M} 06-2 \mathrm{X} / 6-$ $31 \mathrm{G}(\mathrm{d}, \mathrm{p}))$ and the corresponding HOMO plotted with Gaussview at an isosurface value of 0.05 au.

\section{Conclusions}

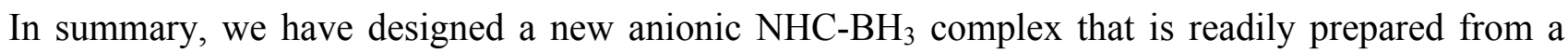
silicate-based abnormal adduct or simple unfunctionalised $\mathrm{IPr}-\mathrm{BH}_{3}$. This complex is isolable and the crystal structure of the anionic IPr- $\mathrm{BH}_{3}$ complex indicates that the lithium counterion is not close to the weakly coordinating anion but nearby the borane moiety interacting with the three hydrogen atoms. The anionic nature of the species confers an increased hydridicity compared to simpler $\mathrm{IPr}_{\mathrm{B}} \mathrm{BH}_{3}$ analogue and the reduction of 4-bromobenzaldehyde could be achieved without the use of an additive. DFT calculations were carried out on this system and showed an increase of the HOMO energy, which may be in part responsible of the high reactivity observed experimentally.

Data availability. Crystallographic data for the structures reported in this Article have been deposited at the Cambridge Crystallographic Data Centre, under deposition numbers CCDC 1575950 (9a). Copies of the data can be obtained free of charge via https://www.ccdc.cam.ac.uk/structures/. All other data supporting the findings of this study are available within the Article and its Supplementary Information, or from the corresponding authors upon reasonable request. 


\section{REFERENCES}

(1) S.-H. Ueng, M. Makhlouf Brahmi, E. Derat, L. Fensterbank, E. Lacôte, M. Malacria, D. P. Curran, J. Am. Chem. Soc. 2008, 130, 10082-10083.

(2) D. P. Curran, A. Solovyev, M. Brahmi Makhlouf, L. Fensterbank, M. Malacria, E. Lacôte, Angew. Chem. Int. Ed. 2011, 50, 10294-10317.

(3) a) M. Horn, H. Mayr, E. Lacôte, E. Merling, J. Deaner, S. Wells, T. McFadden, D. P. Curran, Org. Lett. 2012, 14 , 82-85. b) Q. Chu, M. Makhlouf Brahmi, A. Solovyev, S.-H. Ueng, D. P. Curran, M. Malacria, L. Fensterbank, E. Lacôte, Chem. Eur. J. 2009, 15, 12937-12940.

(4) a) D. M. Lindsay, D. McArthur, Chem. Commun. 2010, 46, 2474-2476. b) L. B. de Oliveira Freitas, P. Eisenberger, C. M. Crudden, Organometallics 2013, 32, 6635-6638. c) T. Liu, L.-Y. Chen, Z. Sun, J. Org. Chem. 2015, 80, 11441-11446. d) B. S. N. Huchenski, M. R. Adams, R. McDonald, M. J. Ferguson, A. W. H. Speed, Organometallics 2016, 35, 3101-3104. e) A.-L. Vallet, S. Telitel, J. Lalevée, E. Lacôte, Hel. Chim. Acta 2019, 102, e1900198.

(5) J. Qi, F.-L. Zhang, J.-K. Lin, Q. Zhao, B. Li, L.-X. Liu, Y.-F. Wang, Angew. Chem. Int. Ed. 2020, 59, 12876-12984.

(6) F. L. Zhang, Y. F. Wang, in: L. Fensterbank, C. Ollivier (Eds), Science of Synthesis: Free Radicals: Fundamentals and Applications in Organic Synthesis 1, Thieme, Stuttgart 2021, p. 381-429)

(7) T. Taniguchi, Eur. J. Org. Chem. 2019, 6308-6319.

(8) M.-A. Tehfe, M. Makhlouf Brahmi, J.-P. Fouassier, D. P. Curran, M. Malacria, L. Fensterbank, L.; Lacôte, E.; Lalevée, J. Macromolecules 2010, 43, 2261-2267.

(9) J. Monot, A. Solovyev, H. Bonin-Dubarle, E. Derat, D. P. Curran, M. Robert, L. Fensterbank, M. Malacria, E. Lacôte, Angew. Chem. Int. Ed. 2010, 49, 9352-9355.

(10) a) T. Matsumoto and F. P. Gabbaï, Organometallics 2009, 28, 4252-4253. b) A. Prokofjevs, J. W. Kampf, A. Solovyev, D. P. Curran, E. Vedejs, J. Am. Chem. Soc. 2013, 135, 15686-15689. c) J. Lam, L. L. Cao, J. M. Farrell, D. W. Stephan, Dalton Trans. 2020, 49, 1839-1846.

(11) a) M. Toure, O. Chuzel, J.-L. Parrain, J. Am. Chem. Soc. 2012, 134, 17892-17895. b) W. Dai, S. J. Geib, D. P. Curran, J. Am. Chem. Soc. 2019, 141, 3623-3629.

(12) D. Holschumacher, T. Bannenberg, C. G. Hrib, P.G. Jones, M. Tamm, Angew. Chem. Int. Ed. 2008, 47, $7428-7432$. 
(13) P. A. Chase, D. W. Stephan, Angew. Chem. Int. Ed. 2008, 47, 7433-7437.

(14) For leading recent reviews, see: a) D. W. Stephan, Acc. Chem. Res. 2015, 48, 306-316. b) D. W. Stephan, G. Erker, Angew. Chem. Int. Ed. 2015, 54, 6400-6441. c) D. W. Stephan, J. Am. Chem. Soc. 2015, 137, 10018-10032. d) J. Paradies, Angew. Chem. Int. Ed. 2014, 53, 3552-3557.

(15) For selected reviews, see: Hopkinson, M. N.; Richter, C.; Schedler, M.; Glorius, F. Nature 2014, 510, 485-496. b) Diez-Gonzalez, S.; Marion, N. ; Nolan, S. P. Chem. Rev. 2009, 109, 3612 3676. c) Nolan, S. P. N-Heterocyclic Carbenes in Synthesis, Wiley-VCH, Weinheim, 2006.

(16) S. Kronig, E. Theuergarten, C. G. Daniliuc, P. G. Jones, M. Tamm, Angew. Chem. Int. Ed. 2012, 51, 3240-3244.

(17) a) E. L. Kolychev, S. Kronig, K. Brandhorst, M. Freytag, P. G. Jones, M. Tamm, J. Am. Chem. Soc. 2013, 135, 12448-12459. b) Andrea Winkler, Kai Brandhorst, Matthias Freytag, Peter G. Jones, Matthias Tamm, Organometallics 2016, 35, 1160-1169.

(18) A. Nasr, A. Winkler, M. Tamm, Coord. Chem. Rev. 2016, 316, 68-124.

(19) a) E. F. Perozzi, J. C. Martin, J. Am. Chem. Soc. 1979, 101, 1591-1593. b) E. F. Perozzi, R. S. Michalak, G. D. Figuly, W. H. Stevenson, D. Dess, M. R. Ross, J. C. Martin, J. Org. Chem. 1981, 46, 1049-1053.

(20) a) G. Lemière, A. Millanvois, C. Ollivier, L. Fensterbank, Chem. Rec. 2021, 21, 1119-1129. b) F. Medici, J. Maury, G. Lemière, L. Fensterbank, Chem. Eur. J. 2019, 25, 9438-9442.

(21) F. Medici, G. Gontard, E. Derat, G. Lemière, L. Fensterbank, Organometallics 2018, 37, 517-520.

(22) Y. Wang, B. Quillian, P. Wei, C. S. Wannere, Y. Xie, R. B. King, H. F. Schaefer, P. v. R. Schleyer, G. H. Robinson, J. Am. Chem. Soc. 2007, 129, 12412-12413.

(23) Y. Wang, Y. Xie, M. Y. Abraham, P. Wei, H.F. Schaefer, III, P. v. R. Schleyer, G. H. Robinson, Organometallics 2011, 30, 1303-1306.

(24) a) A. Solovyev, E. Lacôte, D. P. Curran, Org. Lett. 2011, 13, 6042-6045. b) A. A. Grineva, D. A. Valyaev, V. César, O. A. Filippov, V. N. Khrustalev, S. E. Nefedov, N. Lugan, Angew. Chem. Int. Ed. 2018, 57, $7986-7991$.

(25) a) T. Taniguchi, D. P. Curran, Org. Lett. 2012, 14, 4540-4543. b) V. Lamm, X. Pan, T.Taniguchi, D. P. Curran, Beilstein J. Org. Chem. 2013, 9, 675-680.

(26) S. Antoniotti, V. Dalla, E. Duñach, Angew. Chem. Int. Ed. 2010, 49, 7860-7888. 
(27) J. C. Walton, M. Makhlouf Brahmi, L. Fensterbank, E. Lacôte, M. Malacria, Q. Chu, S.-H. Ueng, A. Solovyev, D. P. Curran, J. Am. Chem. Soc. 2010, 132, 2350-2358.

\section{Acknowledgments}

We thank Sorbonne Université, PSL and CNRS for funding. We are grateful to Jérémy Forté and Geoffrey Gontard for the XRD analyses. This work was granted access to the HPC resources of the HPCaVe centre at Sorbonne Université.

\section{Competing Interests}

The authors declare no competing interests.

\section{Additional information}

Correspondence and request for materials should be addressed to L.F. or G.L. 